\section{FORMATION OF PLANETARY SYSTEMS}

A CONSIDERABLE amount of interest has been shown in recent times on the subject of the origin of planets and satellites, and various theories have been developed with the primary object of circumventing the angular momentum difficulty. A recent paper by B. M. Peek, entitled "The Formation of Planetary Systems" (J. Brit. Astro. Assoc., 53, 1 ; December, 1942), puts forward a theory which possesses at least the merits of simplicity. He starts off with a quotation from Sir James Jeans's "Astronomy and Cosmogony" (1928), which attempts to explain the angular momentum of the nebulæ: "Any currents or motion in the original medium would contribute angular momentum to the nascent nebulæ, and as these shrank to nebular dimensions, the constancy of angular momentum would result in fairly rapid rotations of the shrunken masses". Peek extends this view to the next order of condensation--the starsand is thus able to explain how the necessary angular momentum of the solar system, and other possible planetary systems toó, can be accounted for.

Starting with a portion of the galaxy having a nearly uniform distribution of matter, Peek postulates the beginning of the gravitational instability which produces stars, and further postulates that the random currents in the medium contribute angular momentum to these nascent stars. After a time any diffuse star rotating about an axis which is perpendicular to its equatorial or invariable plane will have most of its angular momentum concentrated close to the rim of this plane. The system has no resemblance to Laplace's nebula, which was supposed to rotate almost like a rigid body. For this reason the main bulk of the star will be almost spherical, not lenticular, as contraction proceeds. In time, however, the small portion of matter at the rim, which received its momentum from the original current, will have communicated some of its motion to other portions in the immediate vicinity, owing to viscosity. The shrinking of the star is necessarily accompanied by an increased angular velocity, in order that the angular momentum may be preserved, and finally portions of matter will be expelled from the periphery and will describe orbits about the still shrinking star. Some quantitative results are given, among which reference may be made to one in particular. Peek has calculated that if the original current had the same order of mass as all the planets combined and moved with a velocity of two metres per second, this current would have been able to endow the whole of the solar system with its observed angular momentum.

By the time all the matter had been shed, a small fraction of the angular momentum would have been communicated to the condensing nucleus, and this may be the explanation of the rotation of the sun in a plane which does not differ very much from the invariable plane. It is suggested that after the main nebula collapsed into diserete condensations, stray wisps of the material composing the nebula, possessing random velocities, would hang about in conditions of unstable equilibrium between the stars in process of formation, and would finally be captured by one or the other of these. Here is a tentative explanation of the origin of the long-period comets. The theory is also able to explain the origin of the satellites and especially their direct motion, but it is admitted that retrograde satellites and also a system like that of Uranus present difficulties. Periodic comets may have been formed from matter left over from the planetary condensations.

No detailed explanation is attempted regarding the manner in which matter would be shed from the contracting mass, though certain possibilities are suggested. This particular part of the subject involves very abstruse mathematics dealing with gas-kinetics, and it is to be hoped that this branch will be developed further. It is conceivable that the theory may encounter some of its greatest difficulties here.

\section{HEALTH IN INDUSTRY}

$T$ $\mathrm{HE}$ importance of securing, in the crisis of manpower and woman-power through which Great Britain is now passing, that there is no waste of labour and that the full woman-power and manpower of the country is utilized to the maximum extent possible in furtherance of the nation's war effort-though it should be noted that the latter is not to be interpreted too narrowly-is now generally appreciated. As the last report of the Chief Inspector of Factories showed, the importance of eliminating the loss of man-hours and woman-hours due to accidents and to sickness is still far from being realized. Nor, as that report and successive reports of the Select Committee on National Expenditure have indicated, have managements either in industry or in Government departments and factories learnt the lessons and applied to good purpose the experience acquired during the War of 1914-18.

That truth is well emphasized in the third report of the 1942-43 session from the Select Committee on National Expenditure. Here the results of the investigations of the Committee on the health and welfare of women in war factories are detailed, and the observation recorded at the outset that little attention seems to have been paid to many of the constructive suggestions contained in earlier reports on health and welfare problems would justify this further inquiry. The relation of health to production is indeed one of the widest interest, as well as of growing importance as the demands of the War grow more imperative. It involves the co-operation of the worker as well as of factory management and of the Government.

Broadly speaking, an efficient general state of health in industry depends on the improvement and maintenance of what is commonly called physical fitness ; the prevention of diseases and of accidents ; the treatment of sick and injured persons and their rehabilitation to fit them for return to industry. The problem to-day is largely one of the most economical use of women, particularly in view of the breakdown of any system of medical examination as to the fitness of women for factory work before they are transferred to work away from home.

The results of this inquiry are set forth in three main divisions : health and welfare within the factory, and, secondly, outside the factory ; and the State and industrial health. In regard to the first, matters relating to the maintenance of health can be grouped under three general headings : $(a)$ physical amenities, such as the provision of satisfactory canteens, cloakrooms, rest-rooms, etc. ; (b) medical provisions, such as first-aid, preventive measures for specific industrial diseases, and the general medical supervision of the 
life of the factory; and (c) general oversight, such as the administrative and executive action which has to be undertaken by welfare or personnel officers. While the general level of physical amenities is on the whole satisfactory and in many factories the standard reached is high, the Committee raises a number of matters in relation to canteens, including inadequate time for meals, and to cleanliness and rest-rooms, which should be brought to notice.

It is recommended next that the Government should give the closest attention to the problem of securing a satisfactory industrial medical service, at least within all the factories engaged on Government work. In this connexion the Committee considers that greater use could be made of women medical practitioners and recommends further that consideration should be given to the question of establishing a centralized employment register for trained nurses. Once again the recommendations that further energetic measures to improve the general standard of lighting in the medium-sized and small factories should be taken by the Ministry of Labour and the supply departments concerned, and that the provision of adequate ventilation in royal ordnance filling factories should be dealt with as a matter of urgency indicate how far we are even yet from harnessing to the service of our war effort even existing scientific knowledge.

Other recommendations in this field are that the supply departments should assist contracting firms to introduce black-out arrangements that will allow of the entrance of a reasonable amount of daylight to workshops, canteens and rest-rooms, and that when new Government factories are in course of construc. tion, or are to be built in the future, expert advice and co-operation should be sought at the earliest stage to ensure that adequate systems of lighting and ventilation are adopted. Further evidence confirms the comments of the Chief Inspector of Factories as to the frequent neglect to take the elementary precaution of training new workers in the use of safety devices, and in regard to hours of work further research and experiment are recommended to determine the best method of arranging a rotation of shifts in royal ordnance factories so as to reduce fatigue and to ensure a minimum of inconvenience to workers and managements. The Committee suggest further that, where a two-shift week is worked, it would be advantageous for departments to organize a five-day week for their women employees.

Once again the crucial importance of personnel management is stressed. The Appointments Board of the Ministry of Labour should carefully consider whether more use could not be made of older men and women with a good educational background as labour officers in factories, and the Select Committee recommends further that the Ministry of Aircraft Production should co-operate with the Ministry of Labour in organizing courses for training personnel managers and welfare workers for firms in the aircraft industry, to which the existing staff in aireraft firms might be sent for refresher courses. It is somewhat disturbing to find that there is still neglect of personnel organization in the aircraft industry, and the Committee also comments on some lack of co-operation between the production staff, labour management and the medical officers in the royal ordnance factories. Examination by the Ministry of Labour of the existing machinery for transferring workers from one district to another with the view of securing a closer relation between regions that are exporting labour and those that are receiving it, so as to ensure that factories are notified of the arrival of new workers in sufficient time to enable the necessary arrangements to be made for their reception, is also recommended, as well as a review of the subject of wartime nurseries.

The latter question falls into the section of the report dealing with health and welfare outside the factory. Here stress is laid on shopping difficulties, which are still acute for most women-workers in many areas, and on the provision of billets, to which a like remark applies. Here the Committee suggests that the regional and local welfare officers of the Ministry of Labour might impress on the more backward firms the advantage to be gained by making better provision for the welfare of workers outside the factory, such as the development of social centres or clubs, and the installation of shower-baths for those unable to obtain baths.

The section of the report which deals with the State and industrial health is of major interest to scientific workers. Discussing first the allocation of responsibilities, the Committee agrees with the broad division of functions between the Ministry of Labour and the supply departments, which should carry a joint responsibility for the maintenance of good personnel management. It is recommended that the factory inspectorate should be relieved of any tasks that can be transferred elsewhere without loss of efficiency, so that the inspectorate may be free to concentrate on the maintenance of good standards of safety and health. It is pointed out, however, that co-operation between the inspectorate and those responsible for the royal ordnance factories has not been as full as it might be. The constitutional relation. ship is not altogether easy, and the medical branch of the factory inspectorate from its composition has neither a staff sufficient to provide advice and instruction on a wide scale nor the authority to ensure that the advice it is able to proffer is accepted by those who need it most. Again, while the Ministry of Labour's welfare officers have done much useful work in securing the provision of facilities for the health and welfare of workers outside the factory, difficulty has been experienced in obtaining suitable people for this advisory work by local recruitment, and the Select Committee recommends that the Ministry of Labour should take immediate steps to recruit older women with the right type of experience.

Neither the Ministry of Supply nor the Ministry of Aircraft Production has, in the Committee's opinion, given the attention to the problems of industrial health and welfare in contractor's factories that is desirable, and the Committee recommends the appointment of medical women as additional advisers to both Ministries. The report once again notes the failure of the supply departments to utilize fully the special knowledge of the Industrial Health Research Board, and while expressing the hope that the fullest use will be made of the results of the work now being undertaken, stresses the need also for comprehensive planning.

To meet this need and to place the existing organization for creating and maintaining the standards of industrial health on a surer foundation, the report finally recommends a rearrangement of the medical supervision of indistrial health. First, the medical branch of the factory inspectorate should be enlarged and strengthened. Secondly, a central industrial health advisory committee should be set up forthwith to advise the Ministry of Labour and the supply departments on all questions of industrial health and 
on the co-ordination of medical services to meet the requirements of the war effort. Regional industrial health advisory committees should also be set up to advise the Ministry of Labour, the regional boards and employers on the co-ordination and extension of industrial health centres in each region. A central bureau should be established for collecting, abstracting and disseminating information and literature relating to all questions of industrial medicine. The need for this is particularly stressed, including the publication of a bulletin, and the bureau might be modelled on similar organizations existing in other fields of applied science. Working in close association with the British Medical Association, the Medical Research Council (particularly the Industrial Health Research Board), and the Association of Industrial Medical Officers, and with an enlarged and strengthened organization of medical inspectors of factories, these committees should do much to reduce the incidence both of industrial disease and of general sickness among industrial workers and others, and thus materially increase the volume of output with a corresponding reduction in cost to the nation.

\section{FORTHCOMING EVENTS}

(Meeting marked with an asterisk is open to the public)

\section{Saturday, February 13}

IRON AND STEEI INSTITUTE (JOINT MMETING WITH THE SHEFFIELD METALLURGIOAL ASSOOIATION, THE SHEYFTELD SOCIETY OF ENGINGERS

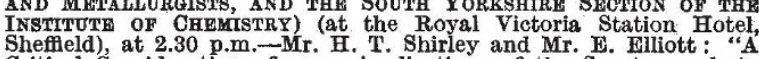
Critical Consideration of some Applications of the Spectrograph to Critical Consideration

Monday, February 15

ROYAL GEOGRAPHICAL SOCIETY (at Kensington Gore, London, S.W.7), at 8 p.m.-Dr. Kaare Rodahl: "The Swedish-Norwegian Expedition to North-East Greenland, 1939-1940".

\section{Tuesday, February 16}

Royal Society of ARTs (Dominions aNd Colonizs SECTion) (at John Adam Street, Adelphi, London, W.C.2), at 1.45 p.m.-Dr. S. S. Pickles: "Rubber, Natural versus Synthetic".

SOCIETY OF CHEMICAL INDUSTRY (JOINT MEETING OF THE AGRIOULTURE GROUP AND THE LONDON SECTION) (at the London School of Hygiene and Tropical Medicine, Keppel Street, London, W.C.1), at 2.30 p.m.-Prof. G. W. Robinson: "Methods and Interpretation of Soil Analysis". ROYAL INSTITUTION (at 21 Albemarle Street, London, W.1), at
3 p.m.- - Sir Lawrence Bragg, F.R.S.: "The Solid State" (iv) "Plusplus Compounds".*

INSTITUTION OF ELECTRICAL ENGINBERS (WIRELESS SBCHION) (at Savoy Place, Victoria Embankment, London, W.C.2), at 5.30 p.m.Discussion on "Electronics in Industry" (to be opened by Mr. $\mathrm{M}$ Cattanes, Mr. G. T. Winch and Mr. A. L. Whiteley).

\section{Wednesday, February 17}

Royau Socierty of ARTs (at John Adam Street, Adelphi, London, W.C.2), at 1.45 p.m.-Dr. C. H. Desch, F.R.S.: "Magnesium" (Peter le Neve Foster Lecture),

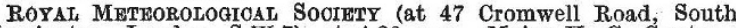
Kensington, London, S.W.7), at 4.30 p.m.-Major H. C. Gunton : "Report on the Phenological observations in the British Isles from December 1941 to November 1942".

INsTrvote OF PHYsIcs (at the Royal Institution, Albemarle Street, Piccadilly, London, W.1), at 6 p.m.-Annual General Meeting. Dr. J. R. Baker : "Freedom in Science".

\section{Thursday, February 18}

CHEMTOAL SOCIETY (at Burlington House, Piccadilly, London, W.1) at 2.30 p.m.-Prof. J. M. Gulland : "Aspects of Nucleotide Chemistry" (Tilden Lecture).

Pharmacedtroal Societry (at 17 Bloomsbury Square, London, W.C.1), at 7 p.m.- Charter Centenary Meeting and Address by the President, Mr. W. Spencer Howells.

\section{Friday, February 19}

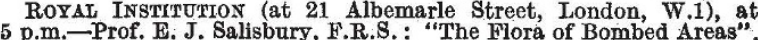
Institution of MEOHANIOAL Enainmers (at Storey's Gate, St. James's Park, London, S.W.1), at 5.30 p.m.-Annual General Meeting. Mr. K. S. Laurie: "Some Textile Finishing Machines".
NORTH-FAST COAST INSTITUTION OF F.NGINEERS AND SHIPBUILDERS (at Bolbec Hall, Newcastle-upon-Tyne), at 6 p.m.-Dr. W. D. Jones : "Powder Metallurgy, its Products and their Various Applications". AssocIATION OF SCIENTIFIC WORKERS (HARPENDEN BRANCH) (at the Congregational Hall, Harpenden, Herts.) at 5 p.m.-Mr. F.

\section{APPOINTMENTS VACANT}

AppLIOATIONS are invited for the following appointments on or before the dates mentioned:

TEACHER OF Mathematics AND Sorgnce at the East Ham Technical College-The Secretary for Education, Education Office, Town Hall Annexe, Barking Road, Hast Ham, London, E.6 (February 19).

LABORATORY STgWARD IN THE DEPARTMENT OF PHYSIOLOGY-The Secretary and Registrar, The University, Bristol (February 20).

PsYchologrst for the Derby Child Guidance Clinic-The Acting Director of Education, Becket Street, Derby (February 22).

TWO SENIOR TECHNICAL ASSISTANTS-The Executive Officer, East Riding of Yorkshire War Agricultural Executive Committee, St. Mary's Manor, Beverley, Yorks. (February 22).

DIREOTOR OF THE GAS RESRARCH BOARD OF THE GAS INDUSTRYThe Secretary, Gas Research Board, Gas Industry House, 1 Grosveno Place, London, S.W.1 (February 22).

LECTURER IN MECHANIOAL ENGINEERING, and an ASSISTANT LECTURER IN MECHANICAL ENGIN⿴kRRING-The Registrar, College of Technology, Manchester 1 (March 1).

MASTER TO TEACH MATHEMATIOS AND ScIENCE at the Bingley Technical School-The Divisional Educational Officer, Education Offices, Bingley, Yorks. (March 7).

Chatr of Chemstry in the University College of North WalesThe Bursar and Acting Registrar, University College of North Wales, Bangor (April 3).

ASSISTANT LECTURER, MAINLY FOR SCIENCE, MATHEMATIOS AND DRAWING-The Principal, County Technical School, Halesowen, Worcs.

TEACHER OF ENGINEERING WORKSHOP PRACTICE AND GENERAL ENGINEERING SUBJECTS at the Burton-on-Trent Technical Institute and Junior Technical School-The Secretary and Director of Education, Education Offices, Guild Street, Burton-on-Trent.

SPEECH THERAPIST-The Education Officer, County Hall, Wakefleld. Part-Timi Demonstrator in The Physics Departiment-Prof. H. Dingle, Imperial College of Science and Technology, South Kensington, London, S.W.7.

LABORATORY ASSISTANT FOR SCHOOL LABORATORY-The Senior Science Master, The Science Schools, Harrow School, Harrow, Middx.

\section{REPORTS and other PUBLICATIONS}

\author{
(not included in tho monthly Books Supplement)
}

Great Britain and Ireland

Post-War Planning and Reconstruction. Pp. 48. (London: Institution of Municipal and County Engineers.) 18 .

\section{Other Countries}

Commonwealth of Australia: Council for Scientific and Industrial Research. Pamphlet No. 113: Drainage Investigations in the Horticultural Soils of the Murray Valley. By A. L. Tisdall. Pp. $23+1$ plate. Pamphlet No. 115: Studies on the Shrinkproofing of Wool, $1:$ The Industrial Development of the Freney-Lipson Process of Holeproof, Ltd., Melbourne ; 2 : Further Studies on the Prevention of Shrinkage in Wool Goods, by M. Lipson and Carmel J. Clyne ; $3:$ Experimental Zeidler. Pp. 33. (Melbourne : Government Printer.)

Public Library of South Australia. First Report of the Libraries Board of South Australia, January to June, 1940, with the Annual Report, July, 1940, to June, 1941. Pp. 8. (Adelaide: Government Printer.)

Forest Research Institute, Dehra Dun. Indian Forest Leaflet No. 21 : How to Identify Timbers, Part 1: Hints on the Identiflcation of Indian Timbers. By K. Ahmad Chowdhury. Pp. ii $+5+2$ plates. 4 annas; 6d. Indian Forest Leaflet No. 24: Plywood Containers. By Sultan Mohammad. Pp. ii $+5+2$ plates. 4 annas; $6 d$. Indian Forest Leaflet No. 25: How to Identify Timbers, Part 2: Timbers for Helves and Tool Handles. By K. Ahmad Chowdhury. Pp. 6-16.
4 annas; 6d. (Dehra Dun: Forest Research Institute.) annas; 6d. (Dehra Dun: Forest Research Institute.) [81 f Resin Solutions, Part 4: The Relationship between Solvent-Power, Gelation Capacity and Viscosity of Shellac Solutions in Mixed Solvents. By Dr. Santi Ranjam Palit. Pp. 14. 1 anna. Bulletin No. 48: Physical Chemistry of Resin Solutions, Part 5: The Solvent-Solute Relationship of Resins in Mixed Solvents. By Dr. Santi Ranjam Palit. Pp. 12. 4 annas. Technical Note No. 7 : A Simple Method of Preparing Pure Resin from Shellac. Bv Dr. Santi Ranjam Palit. Pp. 5. Nam. kum : Indian Lac Research Institute.)

Society of Biological Chemists, India. Annual Review of Biochemical and Allied Research in India. Vol. 12 for 1941. Pp. iit $84+$ xix. (Bangalore: Society of Biological Chemists.) 3 rupees; 68 . 